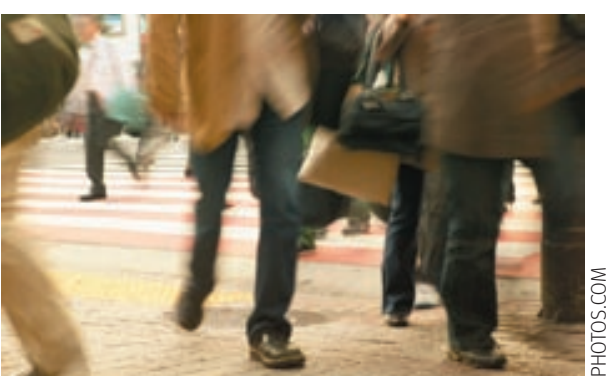

\section{INSTITUTIONAL RACISM}

\section{Editorial is unduly provocative}

As black psychiatrists working in the NHS, we find McKenzie and Bhui's editorial unhelpful and unduly provocative. ${ }^{1}$ For example, although it is possible that racism has a role in increasing detention rates among black patients, the editorial ignores other well established and, in our view, more important factors.

In our combined clinical experience, which includes acute adult, forensic, and child and adolescent psychiatry and many Mental Health Act assessments, one of the main reasons for increased detention rates for black patients is an inadequate community support network. Supportive intermediaries (such as family members) can increase treatment adherence, detect early relapse signs, and enable early noncoercive intervention. ${ }^{2}$ In our experience, compared to other ethnic minorities, the relative inadequacies of support networks predispose black patients to adverse care pathways resulting in crisis and police intervention and disproportionate use of the Mental Health Act. This experience is supported by the AESOP study, which found that black patients were more likely to live alone. ${ }^{3}$

We are neither blaming the victim nor shooting the messenger, but blanket invoking of racism is too simplistic and fails to acknowledge other difficulties in black communities, some of which we can tackle better by reflectively looking inward rather than outward.

Cornelius Ani specialist registrar in child and adolescent psychiatry, Academic Unit of Child and Adolescent Psychiatry, Imperial College, London W2 1PG c.ani@imperial.ac.uk Obeagaeli Ani locum consultant child and adolescent psychiatrist, Hertfordshire Partnership NHS Trust, Elstree Way Clinic, Borehamwood WD6 1JT
Competing interests: None declared.

1 McKenzie K, Bhui K. Institutional racism in mental health care. BMJ 2007;334:649-50. (31 March.)

2 Singh SP, Burns T. Race and mental health: there is more to race than racism. BMJ 2006;333:648-51.

3 Morgan C, Mallett R, Hutchinson G, Bagalkote H, Morgan K, Fearon P, et al. Pathways to care and ethnicity. 1: Sample characteristics and compulsory admission. Report from the AESOP study. BrJ Psychiatry 2005;186:281-9.

\section{Article too strong? I think not}

Although I understand the results of AESOP and the logic of Ani and Ani's argument (previous letter), ${ }^{1} \mathrm{I}$ fail to see how a lack of community supports can be allowed to justify restraint or the illinformed ethnocentric misbehaviours of the NHS (or any institution that claims to care).

Unless and until every potential confounder to providing a healthy intervention is rooted out, then nothing will change. After all, if hospitals, in Ani and Ani's view, continue to support lack of community or family cohesion by admitting people because of inadequate support, what will ever happen to change those very communities and families in a more positive direction? Perhaps they are in the state they are in precisely because these folk feel so systematically enfeebled.

And, surely, this is how we help to "make mental health everyone's business"?

Christopher L Manning chief executive officer, Primhe (Primary care mental health and education) Teddington, Middlesex TW119HG chris.manning@primhe.org Competing interests: None declared.

1 McKenzie K, Bhui K. Institutional racism in mental health care. BMJ 2007;334:649-50. (31 March.)

\section{NEW MENTAL HEALTH BILL}

\section{Bill aims to protect people at times of high risk}

Crichton and Darjee claim that the new mental health bill is insufficiently concerned with care and treatment. ${ }^{1}$ The bill's aim is to ensure that people with mental disorder receive the treatment they need at times of high risk. This will benefit patient and public safety $-14 \%$ of the 1300 patient suicides that occur annually in England and Wales and $25 \%$ of the 52 patient homicides are preceded by refusal to take medication-but the starting point will be better care.

The bill introduces supervised community treatment. A similar power exists in many countries, including Scotland (where the authors work). Patients will be eligible for this treatment only if they are already detained in hospital for treatment-a safeguard that goes beyond what is in the Scottish legislation. The bill also removes the "treatability test" that currently acts as an impediment to care for some people with personality disorder.

Crichton and Darjee claim, without evidence, that an overemphasis on public safety will be counterproductive. But whose overemphasis are they referring to? The House of Lords has amended the bill so that supervised community treatment cannot be used for the suicidal patient, and the Mental Health Alliance, described by the authors as a "remarkable coalition," has asked the government not to reverse this change. Protection for the violent patient but not the suicidal patient? Remarkable indeed.

Louis Appleby national clinical director for mental health Department of Health, London SW1A 2NS

louis.appleby@dh.gsi.gov.uk

Competing interests: LA advises the government on mental health policy.

1 Crichton J, Darjee R. New mental health legislation. BMJ 2007;334:596-7. (24 March.)

\section{GLOBAL PARTNERSHIP}

\section{NHS chief must direct that time overseas is an asset}

Rapid responses on 30 March to the editorial on global health partnerships produced something special: a letter from the chief executive of the Medical Research Council and president of the Academy of Medical Sciences, followed by three letters from coalface workers showing the disastrous effects of Modernising Medical Careers (MMC) as they are experiencing it. ${ }^{12}$ This cluster follows letters from the major UK overseas research institutions, ${ }^{3}$ all the tropical medicine schools, and Médecins sans Frontières (MSF UK). ${ }^{2}$

Blakemore and Bell call for mobility between Britain and the rest of the world for clinicians while maintaining their career 
security, and they cite calls for the same thing from others. But in a giant organisation like the NHS "calling for" counts for nothing, even if the call comes from the prime minister or the chief medical officer. Middle managers spend their days trying to discover what they are being directed to do and then trying to do it, usually with sufficient general awareness to know that this contradicts something else that they are being directed to do.

MMC has arisen from a "call for," or consultation document, published in 2000. ${ }^{4}$ That call has now been translated, doubtless via almost uncountable directives through chains of middle managers, into the horror of MMC 2007. The flexibility of the original call is now a depressing rigidity, and mediocrity is the ruling standard throughout. The chief executive of the NHS will just have to follow the call of his predecessor, Lord Crisp, and direct that time spent overseas is always to be counted as a strong asset in promotion or entry to further training, and that any NHS trust that has not made an effort to link with an institution overseas is going to have to explain itself to him.

Ed Cooper retired paediatrician, London N4

edcooper@doctors.org.uk

Competing interests: None declared.

1 Whitty CJM, Doull L, Nadjm B. Global health partnerships. BMJ 2007;334:595-6. (24 March.)

2 Electronic responses. Global health partnerships. www. bmj.com/cgi/eletters/334/7594/595

3 Molyneux M, Marsh K, White N, Farrar J, French N, Day N, et al. UK doctors are already put off by changes in training. BM/2007;334:709-10. (7 April.)

4 Department of Health. A health service of all the talents: Developing the NHS workforce - consultation document on the review of workforce planning. London: DoH, 2000. www.dh.gov.uk/en/Publicationsandstatistics/ Publications/PublicationsPolicyAndGuidance/DH_ 4007967

\section{DE-PROFESSIONALISING DOCTORS}

\section{Academy of Royal Colleges spoke out in 2002}

Drife writes: "So when they set up new bodies to replace key functions of the royal colleges, who resisted? Not the colleges or faculties, all 27 of them with their 28 opinions. ${ }^{1}$

The facts are different. The Academy of Medical Royal Colleges unanimously approved an article for publication, which the $B M J$ published in $2002,{ }^{2}$ under my name as chairman of the academy at the time, with the title "De-professionalising doctors." So all the colleges and faculties could and did agree a single opinion and publicly issued a warning with this striking title.

Simultaneously, the academy gave written advice to the Department of Health, important parts of which were rejected.

Denis Pereira Gray emeritus professor, University of Exeter ExeterEX2 4TJ d.pereiragray@doctors.org.uk

Competing interests: DPG was chairman, Academy of Medical Royal Colleges, 2000-2.

1 Drife JO. Confessions of a collaborator. BMJ 2007;334:640. (24 March.)

2 Pereira Gray D. De-professionalising doctors? BMJ 2002;324:627-8.

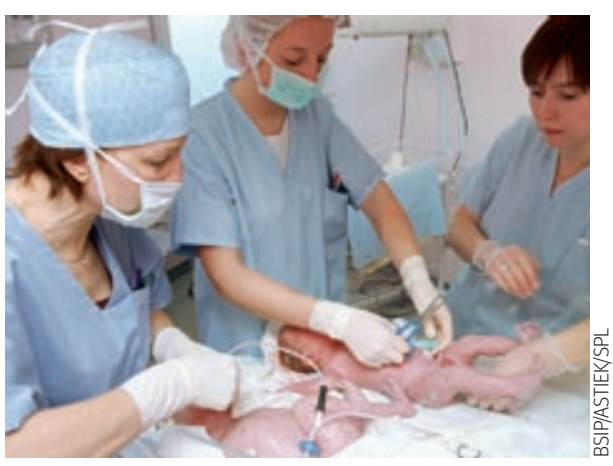

PERINATAL DEATH IN TWINS

\section{Author's reply on absolute risk}

In response to Cheetham, ${ }^{1}$ as stated, our study was able only to address the relative risk to the second twin given the nature of the data. ${ }^{2}$ We previously addressed both absolute risk and the effect of caesarean section using record linkage of the Scottish Morbidity Record and the Scottish Stillbirth and Infant Death Enquiry. This linkage provides both the numerator and denominator required for the comparisons proposed.

The absolute risk of perinatal death for second twins born at term was 1 in 270 for all causes, 1 in 350 for death due to intrapartum anoxia, and 1 in 500 for anoxic death due to a mechanical cause. ${ }^{3}$ Planned caesarean section is associated with a lower risk of perinatal death and, if causality is assumed, the number needed to treat is 264 caesarean deliveries to prevent each death. ${ }^{4}$ These numbers reflect higher absolute risks than calculated by Cheetham. This may reflect flaws in the assumptions of his calculations. It may also reflect the observation that, although the second twin was at increased risk of death at term in both populations, the relative risk was higher in Scotland. We cannot address whether this reflects a greater absolute risk to the second twin in Scotland or to the first twin in England, Northern Ireland, and Wales.

Gordon C S Smith professor of obstetrics and gynaecology Department of Obstetrics and Gynaecology, Cambridge University, Rosie Hospital, Cambridge CB22SW gcss2@cam. ac.uk
Competing interests: None declared

1 Cheetham C. Absolute risk: better basis for decision making. BM/ 2007;334:651-2. (31 March.)

2 Smith GCS, Fleming KM, White IR. Birth order of twins and risk of perinatal death related to delivery in England, Northern Ireland, and Wales, 1994-2003: retrospective cohort study. BM/ 2007;334:576-8. (17 March.)

3 Smith GC, Pell JP, Dobbie R. Birth order, gestational age, and risk of delivery related perinatal death in twins: retrospective cohort study. $B M /$ 2002;325:1004.

4 Smith GCS, Shah I, White IR, Pell IP, Dobbie R. Mode of delivery and the risk of delivery-related perinatal death among twins at term: a retrospective cohort study of 8073 births. BrJ Obstet Gynaecol 2005;112:1139-44.

\section{HISTORY OF MEDICINE}

\section{Understanding the history of medicine}

Ravichandran says that Andrew Cunningham, in his BBC Radio series The Making of Modern Medicine, tries to make sense of the past in its own terms. ${ }^{1}$ If we try to understand the past in its own terms we will never make sense of it.

For example, ${ }^{2}$ in 1868 (the year after Lister published on antiseptic surgery) John Hughes Bennett, a professor of medicine at Edinburgh, published an article showing that the whole approach of Pasteur and Lister was misconceived: he reported experiments that "proved" that germs generate spontaneously, so one could never create a germ free environment. In his own understanding, Hughes Bennett (who discovered leukaemia) had disproved the germ theory of disease. In our understanding, Hughes Bennett had failed adequately to sterilise his experimental apparatus. If we want to know what really happened we need to use our own science. Proponents of the "make sense of the past in its own terms" school advocate "charitable interpretation," but there are limits to charity in a case like this: no amount of charitable interpretation will make Hughes Bennett right and Pasteur and Lister wrong.

Historians of medicine thus have a simple choice: on the one hand, you can understand the past in its own terms (in which case Hippocrates and Galen saved lives), or, on the other, you can understand the past in the light of modern science (in which case they killed much more often than they cured).

David Wootton professor of history, University of York, York Y010 5DD davidwootton@starrymessenger.co.uk Competing interests: None declared.

1 Ravichandran B. Celebrating the medical past, again. BMJ 2007;334:587. (17 March.)

2 McClure I. David Wootton. Bad medicine: doctors doing harm since Hippocrates. BMJ 2006;333:606. 